\title{
PROCESSOS DE RETEXTUALIZAÇÃO: APARATO TEÓRICO-METODOLÓGICO
}

\author{
RETEXTUALIZATION PROCESSES: THEORETICAL \\ AND METHODOLOGICAL APPARATUS
}

Valfrido da Silva Nunes ${ }^{1}$

\begin{abstract}
RESUMO: Este artigo resulta de um apanhado teórico, em cujo cerne assenta-se a questão da retextualização. O objetivo principal é discutir a problemática referida à luz da Linguística Textual, especialmente por meio da contribuição seminal de Luiz Antonio Marcuschi, e de produções acadêmica filiadas a esse mesmo campo do saber. Nesse sentido, discutem-se as concepções de língua e de texto adotadas no trabalho e elucida-se o conceito de retextualização e os desdobramentos que a questão suscita, tais como: a) as várias possibilidades de retextualização; b) a retextualização nas diversas instâncias da vida social; c) um breve panorama dos estudos sobre retextualização no Brasil; d) a retextualização da fala para a escrita e o modelo de análise proposto por Marcuschi (2010); e) a relação entre retextualização e fenômenos assemelhados (reescrita, refacção e revisão). Palavras-chave: retextualização; reescrita/refacção; revisão.
\end{abstract}

ABSTRACT: This article results from a theoretical catch, emitting core lies the question of retextualization. The main objective is to discuss the problematic, in the light of Textual Linguistics, especially through the seminal contribution of Luiz Antonio Marcuschi, and of academic productions affiliated to this same field of knowledge. In this sense, the conceptions of language and text adopted in the work are discussed and the concept of retextualization is discussed and the consequences that are important, such as: a) the various possibilities of retextualization; b) the retextualization in the various instances of social life; c) a brief overview of the studies on retextualization in Brazil; d) the retextualization of speech for a writing and analysis model proposed by Marcuschi (2010); e) the relation between retextualization and similar phenomena (rewrite, repair and revision).

Keywords: retextualization; rewrite/repair; review.

\section{INTRODUÇÃO}

Este trabalho versa sobre um dos grandes temas da Linguística Textual na atualidade: a retextualização. A bem dizer, trata-se de um fenômeno comum na nossa vida diária, em suas múltiplas instâncias, entretanto nem sempre muito bem compreendido, principalmente quando transposto para a sala de aula e para os livros didáticos, uma vez que muito do que se produz na academia pouco dialoga com a realidade das nossas escolas. Com base nisso, objetivamos apresentar esse tema sem a pretensão de esgotar a questão, mas com o cuidado de não cairmos num reducionismo simplista. Nesse sentido, a proposta de construção desse texto é fazer uma introdução ao tema, de forma a torná-lo um tanto mais didático e acessível àqueles que estão se iniciando nos estudos linguísticos, tais como alunos dos primeiros anos dos cursos de Letras, Pedagogia e áreas afins. Ademais, acreditamos que esta reflexão possa trazer ainda subsídios ao professor de língua portuguesa da educação básica, tanto no nível fundamental quanto no nível médio.

A perspectiva teórica adotada é a da Linguística do Texto, precipuamente por meio de Marcuschi (2010), sem deixar de lado produções de muitos outros pesquisadores que deram continuidade ao estudo desse tema, em diversos programas de pós-graduação do Brasil. Do ponto de vista

\footnotetext{
${ }^{1}$ Doutor em Linguística. Professor e pesquisador do Instituto Federal de Pernambuco (IFPE). Garanhuns/PE - BR. Líder do GEL - Grupo de Estudos em Linguagens (IFPE/CNPq). Contato: fridoval@hotmail.com.
} 
metodológico, o presente trabalho está mais próximo de um estudo de caráter bibliográfico, pois também nos propomos a levantar e apreciar algumas produções acadêmicas que, ancoradas em Marcuschi (2010), tratam do fenômeno da retextualização em diferentes campos da comunicação humana. Por fim, este texto organiza-se retoricamente da seguinte forma: 1) uma seção em que se esclarecem as concepções de língua e de texto adotadas no trabalho e 2) uma seção em que se pretende elucidar o conceito de retextualização e os desdobramentos que a questão suscita, tais como: a) as várias possibilidades de retextualização; b) a retextualização nas diversas instâncias da vida social; c) um breve panorama dos estudos sobre retextualização no Brasil; d) a retextualização da fala para a escrita e o modelo de análise proposto por Marcuschi (2010); e) a relação ente retextualização e fenômenos assemelhados (reescrita, refacção e revisão).

\section{AS NOÇÕES DE LÍNGUA E TEXTO}

Uma primeira observação que se faz necessária diz respeito à concepção de língua adotada neste trabalho. Não se trata de uma perspectiva puramente sistêmica nem exclusivamente discursiva e muito menos de uma abordagem dicotômica que oponha a fala à escrita. Adotamos, portanto, uma visão de língua que não se desvincula das práticas sociais mediadas pela linguagem, levando em consideração os seus usuários e as situações interativas que motivam o uso da língua, seja oral, seja escrita; em outros termos, trata-se de uma concepção sociointeracionista (MARCUSCHI, 2010). Sob esse prisma, o linguístico e o discursivo se entrecruzam, engendrando os fios que tecem a teia da comunicação humana.

A segunda observação refere-se ao conceito de texto, uma categoria complexa e multifacetada, vista por uns apenas como materialidade superficial do discurso e, por outros, como um construto que se confunde com a própria noção de discurso. De qualquer maneira, a nossa opção neste trabalho afina-se com a perspectiva da Linguística Textual, a qual vê o texto como "evento comunicativo em que convergem ações linguísticas, cognitivas e sociais" (BEAUGRANDE, 1997, p. 10). Essa visão de texto é tributária daquilo que Beaugrande e Dressler (1981) denominaram de textualidade, ou melhor, o que faz como que um texto seja de fato um texto, compreendido como uma unidade de sentido. Disso decorrem os sete fatores da textualidade: coerência, coesão, intencionalidade, informatividade, situacionalidade, intertextualidade e aceitabilidade. Nesse caso, o texto é um objeto sociointeracional; em outras palavras, ele é o próprio "lugar de interação entre atores sociais e de construção interacional de sentidos” (KOCH, 2009, p. XII).

\section{O QUE É RETEXTUALIZAÇÃO}

Para iniciar nossa reflexão sobre este tema, que é caro à Linguística Textual, gostaríamos de partir de uma afirmação, proposta por Matencio (2003), acerca desse fenômeno, em que se diz:

textualizar é agenciar recursos linguageiros e realizar operações linguísticas, textuais e discursivas. Retextualizar, por sua vez, envolve a produção de um novo texto a partir de um ou mais textosbase, o que significa que o sujeito trabalha sobre as estratégias linguísticas, textuais e discursivas identificadas no texto-base para, então, projetá-las tendo em vista uma nova situação de interação, portanto um novo enquadre e um novo quadro de referência (MATENCIO, 2003, p. 4).

A nossa predileção por esse conceito justifica-se em razão de a autora contrastar a noção de "textualização" com a de "re-textualização", o que nos parece bastante produtivo. Analogamente, podemos conjeturar que se "refazer" é "fazer novamente" e se "rever" é "tornar a ver", existe algum traço semântico neste prefixo - "re" - que nos conduz a pensar que "retextualizar" acarreta necessariamente uma volta ao que já foi textualizado, ou seja, é preciso "textualizar novamente"

https://periodicos.unifap.br/index.php/letras

Macapá, v. 9, n. 4, $2^{\circ}$ sem., 2019 
ou "tornar a textualizar".

Nesse sentido, "textualizar" implica produzir textos, materializar linguisticamente algo que se quer dizer (por escrito ou oralmente), por meio de operações linguísticas (recursos lexicais e fraseológicos), textuais (estratégias de articulação, paráfrase, resumo, referenciação, modalização etc.) e discursivas (condições de produção, dito, não dito, intencionalidade, situacionalidade, papéis sociais ocupados pelos interactantes, relações de força e de restrições impostas pelo gênero textual, função discursiva do suporte, formas de circulação do gênero etc.).

Por outro lado, "retextualizar" supõe a produção de um novo texto a partir de texto(s) já existente(s). Assim sendo, o fenômeno da retextualização configura-se como uma ação linguageira orientada por outras condições de produção diferentes daquelas do(s) texto(s)-base. Esse, possivelmente, é o cerne da ação de retextualizar, pois daí advém a possibilidade de haver mudança de modalidade linguística, mudança de gênero textual e implicações no plano da intertextualidade e da interdiscursividade. Nessa linha de raciocínio, Marcuschi explica que atividades de retextualização:

são rotinas usuais altamente automatizadas, mas não mecânicas, que se apresentam como ações aparentemente não problemáticas, já que lidamos com elas o tempo todo nas sucessivas reformulações dos mesmos textos numa intricada variação de registros, gêneros textuais, níveis linguísticos e estilos. Toda vez que repetimos ou relatamos o que alguém disse, até mesmo quando produzimos as supostas citações ipsis verbis, estamos transformando, reformulando, recriando e modificando uma fala em outra. (MARCUSCHI, 2010, p. 48).

Essa afirmação do autor mostra-se bastante pertinente por apresentar a retextualização como uma atividade de "reformulação" textual rotineira e automatizada, pois o falante da língua sequer se dá conta de que está redizendo o dizer do outro. Efetivamente, podemos pensar que isso se dá pelo próprio fenômeno da enunciação, que aponta para a irrepetibilidade de todo e qualquer dizer. Nesse sentido, se a retextualização é tão presente nas nossas práticas linguageiras e se tudo que dizemos o fazemos retomando o que já foi dito por outros, podemos sustentar que a retextualização é um fenômeno constitutivo dos usos da linguagem.

\subsection{Possibilidades de retextualização}

Marcuschi (2010, p. 48) apresenta-nos um quadro com quatro possibilidades de retextualização, embora, à época, naquela obra, ele tenha se debruçado somente sobre uma delas ("da fala para a escrita", como se intitula o seu livro). Tais possibilidades podem ser resumidas da seguinte forma:

(a) da fala para a escrita, cuja reformulação mais notável dá-se na mudança das modalidades linguísticas, tal como ocorre na passagem de uma entrevista oral para uma entrevista impressa publicada em revista, por exemplo;

(b) da fala para a fala, em que não há mudança de modalidade linguística, mas de outros níveis (de gênero, de estilo, de registro), tal como acontece em uma conferência e sua respectiva tradução simultânea;

(c) da escrita para a fala, cuja transformação dá-se, mais uma vez, sobretudo, entre modalidades linguísticas, assim como ocorre na passagem de um texto escrito para a sua exposição oral;

(d) da escrita para a escrita, em que, novamente, não há mudança de modalidade linguística, porém em outros níveis, assim como acontece entre um texto escrito e o seu respectivo resumo.

A despeito da proposta de Marcuschi (2010) ser profícua, ela não contempla a transformação 
de textos não verbais ${ }^{2}$, os quais constituem a cultura visual na qual estamos fortemente inseridos. Hoje tem se tornado comum a adaptação de clássicos da literatura, por exemplo, para as histórias em quadrinhos, para o cinema e para a televisão. A nosso ver, caberia, portanto, investigar de que maneira ocorrem essas transformações e se elas se configurariam como processos de retextualização de textos multimodais (NUNES, 2017).

\subsection{A retextualização nas diversas instâncias da vida social}

Como disse Marcuschi (2010, p. 49), "na realidade, nossa produção linguística diária, se analisada com cuidado, pode ser tida como um encadeamento de reformulações, tal o imbricamento dos jogos linguísticos praticados nessa interdiscursividade e intertextualidade". A propósito, Silveira $(2008$, p. 147) inicia um artigo sobre esse tema convidando-nos a refletir sobre um aviso oral dado por um coordenador de curso de uma instituição de ensino anunciando determinado evento e o cartaz afixado no mural desta mesma instituição divulgando este mesmo evento. A autora frisa que entre ambos os gêneros - em que pese o fato de um ser oral e o outro escrito - há mais semelhanças do que diferenças. No nosso ponto de vista, o cartaz funciona como a retextualização de um comunicado oral, da mesma forma que o inverso também pode ser verdadeiro. Essa movência do oral para o escrito e vice-versa sugere mais de uma possibilidade de retextualização, conforme veremos adiante. Nesse sentido, Marcuschi (2010, p. 49) lista uma série de eventos comunicativos, em diferentes domínios discursivos, que se configuram como práticas de retextualização, conforme se pode observar no quadro seguinte.

Fig. 1 - Alguns eventos linguísticos em que ocorre retextualização

\begin{tabular}{|c|c|}
\hline$(1)$ & $\begin{array}{l}\text { A secretária que anota informações orais do(a) chefe e com elas } \\
\text { redige uma carta. }\end{array}$ \\
\hline$(2)$ & $\begin{array}{l}\text { O(a) secretário(a) de uma reunião de condomínio (ou qualquer outra) } \\
\text { encarregado(a) de elaborar a ata da reunião, passando para a } \\
\text { escrita um resumo do que foi dito. }\end{array}$ \\
\hline (3) & $\begin{array}{l}\text { Uma pessoa contando à outra o que acabou de ler no jornal ou na } \\
\text { revista. }\end{array}$ \\
\hline$(4)$ & $\begin{array}{l}\text { Uma pessoa contando à outra o que acabou de ouvir na TV ou no } \\
\text { rádio. }\end{array}$ \\
\hline$(5)$ & $\begin{array}{l}\text { Uma pessoa contando à outra o filme que viu no dia anterior ou o } \\
\text { último capítulo da novela ou as fofocas da vizinhança. }\end{array}$ \\
\hline$(6)$ & Alguém escrevendo uma carta relatando o que ouviu no dia anterior. \\
\hline$(7)$ & $\begin{array}{l}\text { O(a) aluno(a) que faz anotações escritas da exposição do(a) } \\
\text { professor (a). }\end{array}$ \\
\hline$(8)$ & $\begin{array}{l}\text { O juiz ou o delegado que dita para o escrevente a forma final do } \\
\text { depoimento. }\end{array}$ \\
\hline
\end{tabular}

Fonte: Marcuschi, 2010, p. 49, com adaptações.

\footnotetext{
2 Aqui estamos considerando o texto como um fenômeno mais amplo que evolve todas as possibilidades de significar, independentemente do código utilizado. Assim, podemos falar em texto pictórico, texto imagético, texto visual, texto gestual, texto fílmico etc.
}

https://periodicos.unifap.br/index.php/letras Macapá, v. 9, n. 4, $2^{0}$ sem., 2019 
Em nossa pesquisa de mestrado (NUNES, 2020), na qual fizemos um estudo acerca do funcionamento da carta do leitor na mídia impressa, constatamos que esse gênero também emerge de um processo de retextualização, visto que a missiva publicada efetivamente nas páginas do jornal tinha como concepção outro gênero escrito: o e-mail. Assim, ao menos na mídia analisada - o Jornal do Commercio de Pernambuco -, a carta do leitor surge de um processo de transformação (em que ocorrem substituição, inserção e/ou exclusão de informações) que ilustra um caso típico de retextualização da escrita para a escrita (NUNES; SILVEIRA, 2017).

\subsection{Breve panorama de estudos sobre retextualização no Brasil}

Há praticamente uma década e meia, Marcuschi (2010) principiava os estudos acerca da retextualização no Brasil. Naquela ocasião, ele referia quatro trabalhos acadêmicos já realizados que traziam em seu bojo processos de transformação textual, a saber: (i) o cotejo entre a gravação do discurso de um parlamentar italiano com sua cópia estenográfica (CORTELAZZO, 1985 apud MARCUSCHI, 2010); (ii) a geração de narrativas escritas com estrutura monológica, a partir de entrevistas dialógicas (inquirição) de policiais com os suspeitos em pequenos crimes como furtos e fraudes (JÖNSSON \& LINELL, 1991 apud MARCUSCHI, 2010); (iii) a transformação dos depoimentos de testemunhas em assentamentos escritos ditados por juízes durante os inquéritos em processos criminais (ALVES, 1992 apud MARCUSCHI, 2010) e (iv) a produção de artigos de divulgação científica por jornalistas a partir de entrevistas com cientistas (GOMES, 1995 apud MARCUSCHI, 2010).

De lá para cá, muitas pesquisas têm sido empreendidas acerca do tema em tela, cujos resultados estão sistematizados em artigos acadêmicos, dissertações e teses. Neste trabalho, destacaremos algumas dessas publicações, todas disponíveis em formato digital e acessíveis por meio da internet. Utilizando um critério cronológico, agrupamos parte dos trabalhos produzidos sobre retextualização, cujas sínteses podem ser vistas abaixo.

Santos (2006) analisa a retextualização como estratégia de discursividade, por concluintes de Direito, em suas monografias. A autora parte da análise das estratégias de retextualização, procurando observar como o discente constitui-se em sujeito de seu discurso e analisando também as interferências de sua interpretação, no trato com o texto matriz.

Nascimento (2007) apresenta uma análise, na perspectiva da Linguística Textual, do fenômeno da retextualização, focalizando as transformações ocorridas durante a construção do gênero depoimento prestado pelo acusado/réu ao delegado de polícia/juiz, tanto em delegacias de polícia quanto em fóruns. Segundo a autora, os fenômenos linguísticos analisados neste estudo evidenciam que o interrogatório policial/judicial constitui um tipo de "interação assimétrica".

Abasse (2008) investiga a produção do resumo como uma prática escolar resultante da atividade de retextualização. A autora procura configurar um panorama das operações envolvidas naquela atividade, investigando em que grau a malha tópica foi mantida, identificando e analisando as diferentes marcas linguísticas usadas no estabelecimento da coerência entre o texto-fonte e o resumo-escolar.

Oliveira (2009) visa não só a fazer o levantamento de alterações promovidas por retextualizadores na passagem de discursos parlamentares orais para a modalidade escrita como também a realizar a análise dessas alterações com vistas às suas implicações para o sentido do texto. No dizer da autora, a retextualização desses discursos, tendo em vista a importância do que é dito no plenário, deveria primar pela fidelidade ao dito pelo orador e pelo respeito ao seu estilo.

Oliveira (2010) investiga a produção de redações escolares resultantes da atividade de retextualização de um infográfico. A autora busca configurar um panorama das operações envolvidas na atividade citada, por meio da Teoria da Estrutura Retórica (Rhetorical Structure Theory), observando quais as relações retóricas presentes no infográfico e quais as presentes nas redações escolares, de modo a estabelecer um comparativo entre os dois textos, ao se investigar em que grau a estrutura

https://periodicos.unifap.br/index.php/letras

Macapá, v. 9, n. 4, $2^{\circ}$ sem., 2019 
retórica foi mantida.

Moura (2011) apresenta a análise da retextualização de textos didáticos para o ensino profissional de nível técnico realizada por redatores técnicos, a partir do cotejo com os textos base que lhes deram origem. O cotejo texto-base/texto-final possibilita uma investigação numa perspectiva comunicacional-discursiva, em que os sujeitos envolvidos no processo são estudados a fim de se evidenciar a existência de um contrato de comunicação com dupla aplicação, característico dos processos tradutórios.

Benfica (2012), por sua vez, propõe reflexões sobre a noção de gênero que subjaz às propostas de produção de textos realizadas a partir de atividades de retextualização em livros didáticos de Língua Portuguesa do Ensino Fundamental. O estudo apresenta uma análise exploratória realizada em uma coleção de livro didático de português, buscando investigar se as propostas apresentadas supõem o funcionamento discursivo dos gêneros envolvidos no processo de retextualização.

Silva (2013) focaliza os processos de retextualização na exposição oral acadêmica, com o objetivo de evidenciar as suas possibilidades de constituição e de contribuir para a reflexão sobre o que permite e/ou o que dificulta a sua produção. Feita uma comparação entre a macroestrutura dos textos-base e as estratégias de retextualização mobilizadas nos slides eletrônicos (textos de apoio), a autora constatou que nem sempre o conteúdo retextualizado corresponde ao que é sugerido nos textos de origem e verificou que o conteúdo exposto também é contraditório em relação a esses textos.

Demétrio (2014) propõe o uso da tradução sob a perspectiva da retextualização como uma estratégia para a produção textual em sala de aula de língua estrangeira. A pesquisa realizou-se com um grupo de estudantes do Curso de Letras/Espanhol/EaD/UFSC e concretizou-se por meio de uma atividade em que os alunos traduziram um texto - originalmente produzido no gênero reportagem e veiculado pelo jornal argentino La Nación, o qual versava sobre o tema da reciclagem do lixo nas grandes cidades - em um novo texto concebido no gênero carta do leitor, que tratava do mesmo tema.

Alves (2015) estudou a oralidade e a escrita no que tange à retextualização do oral para o escrito e vice-versa. Para tanto, cotejou alguns materiais produzidos pelo Conselho de Ensino, Pesquisa e Extensão (ConsEPE) da Universidade Federal do ABC. Tratou-se de um corpus constituído de três partes: uma relatoria escrita, que é um parecer avaliativo; a transcrição do áudio da apresentação oral dessa relatoria em uma sessão do ConsEPE; e o trecho da ata correspondente a essa apresentação. A conclusão a que se chegou foi a de que aspectos da fala e da escrita entrecruzam-se em maior ou menor escala, dependendo do que se pretende produzir, tendo em vista o efeito, o resultado e o objetivo que se quer alcançar com dada comunicação.

Cavalcanti (2016), em sua tese de doutorado, encetou uma discussão acerca de processos de retextualização (do oral para o escrito) de alunos colaboradores recém-chegados ao ensino médio profissionalizante, integrantes da rede pública federal de ensino de Alagoas, com base na produção textual/discursiva de gêneros opinativos, à luz dos estudos retóricos da linguagem. Os resultados evidenciaram, em alguma medida, que a educação descontinuada, além da suposta ausência do trabalho com a argumentação em práticas de sala de aula, apontada pelos colaboradores da pesquisa, dificultaram a produção de gêneros opinativos nas modalidades oral e escrita desses alunos recém-chegados ao ensino médio profissionalizante.

Dikson (2019) desenvolveu uma consistente pesquisa acerca dos aspectos e processos de retextualização escrita-escrita. O autor apresenta a topicalização e a reformulação textual como estratégias fundamentais nesse processo. Respaldado por pesquisa realizada em contexto pedagógico, o trabalho do autor preenche uma lacuna importante no campo da Linguística Textual brasileira. Ademais, põe em cena gêneros essencialmente multimodais, como as HQ, deixando como legado um consubstanciado aporte teórico-metodológico àqueles que se interessam pela pesquisa nessa área, especialmente no que tange à retextualização entre textos escritos.

Diante deste cenário, resta-nos dizer que as pesquisas sobre retextualização não se restringem ao apanhado acima exposto, já que muitos outros trabalhos não foram aqui citados. Ademais, novas

https://periodicos.unifap.br/index.php/letras

Macapá, v. 9, n. 4, $2^{\circ}$ sem., 2019 
pesquisas sobre o tema continuam em efervescência, sob os mais diferentes enfoques, em diversos programas de pós-graduação. De qualquer maneira, é pertinente ressaltar que o fenômeno da retextualização é, de fato, complexo e transdisciplinar, pois quando observamos apenas os trabalhos aqui referidos, vemos que eles se situam em múltiplas esferas discursivas: jurídica, política, jornalística, administrativa, escolar e acadêmica.

\subsection{A retextualização da fala para a escrita}

Como bem delimitou Marcuschi (2010), naquela ocasião interessava a ele investigar apenas as operações mais importantes nos processos de retextualização da fala para a escrita. De alguma forma, isso é um tanto justificável. Por um lado, à época, o referido pesquisador iniciava os primeiros estudos acerca da retextualização no Brasil; por outro lado, havia um interesse crescente em se discutir a relação oralidade x escrita, com vistas a desfazer mitos e quebrar paradigmas - a relação dicotômica fala x escrita e a supremacia da segunda sobre a primeira -, propondo a noção de um continuum entre ambas, cujo foco consiste em apresentar muito mais semelhanças do que diferenças entre elas.

Marcuschi (2010, p. 47) sublinha que “(...) antes de qualquer atividade de transformação textual, ocorre uma atividade cognitiva denominada compreensão.” De fato, se o retextualizador não compreender o que foi dito oralmente, o texto escrito poderá ficar comprometido. Ademais, retextualizar não se confunde com transcrever, uma vez que esta é apenas a passagem de uma realização sonora para uma realização gráfica, sem mudanças mais sensíveis. Todavia, a transcrição torna-se peça fundamental deste jogo, dado que o texto oral precisa, antes de tudo, ser compreendido e transcrito, seguindo procedimentos convencionalizados. Nas palavras do próprio autor, “(...) há uma atividade onipresente na atividade de transcrição, que é a compreensão. Sempre transcrevemos uma dada compreensão que temos do texto oral" (MARCUSCHI, 2010, p. 51).

Nesse sentido, Marcuschi (2010) aponta algumas variáveis intervenientes no processo de retextualização da fala para a escrita, quais sejam: (a) o propósito ou o objetivo da retextualização; (b) a relação entre o produtor do texto original e o transformador; (c) a relação tipológica entre o gênero textual original e o gênero da retextualização e (d) os processos de formulação típicos de cada modalidade. Todos esses fatores, segundo o autor, evidenciam que a passagem de uma modalidade à outra é uma atividade consciente que segue os mais variados tipos de estratégias. A retextualização da fala para a escrita, entendida como uma espécie de tradução endolíngue, envolve múltiplos aspectos, conforme se pode verificar na figura a seguir.

Fig. 2 - Aspectos envolvidos no processo de retextualização

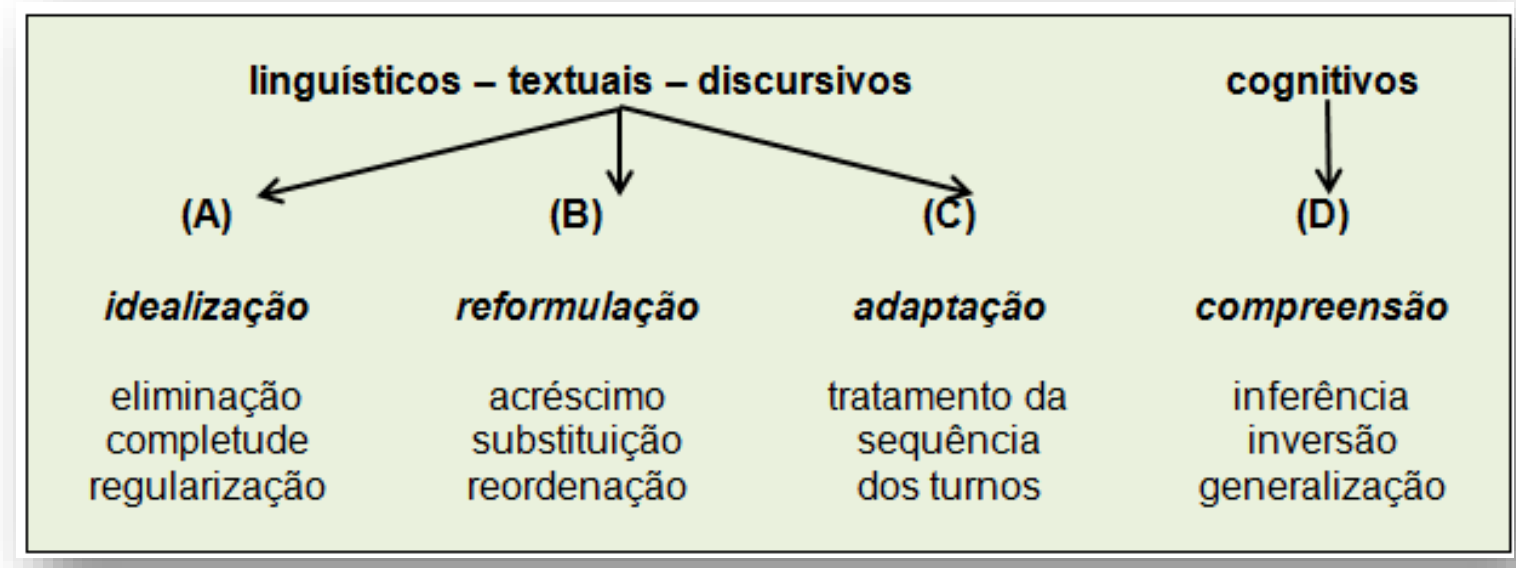

Fonte: Marcuschi (2010, p. 69).

https://periodicos.unifap.br/index.php/letras

Macapá, v. 9, n. 4, $2^{\circ}$ sem., 2019 
Marcuschi (2010) salienta também que toda atividade de retextualização implica uma interpretação prévia que pode ter consequências nada desprezíveis. Esse gesto de interpretação aponta para aspectos de ordem do discurso, reforçando que o processo de retextualização não se circunscreve apenas ao plano textual, mas envolve questões relativas à intertextualidade e à interdiscursividade, conforme afirmou Matencio (2003). A fim de mostrar os caminhos percorridos pelo texto oral na passagem para a escrita, vejamos o diagrama a

seguir.

Fig. 3 - Fluxo dos processos de retextualização

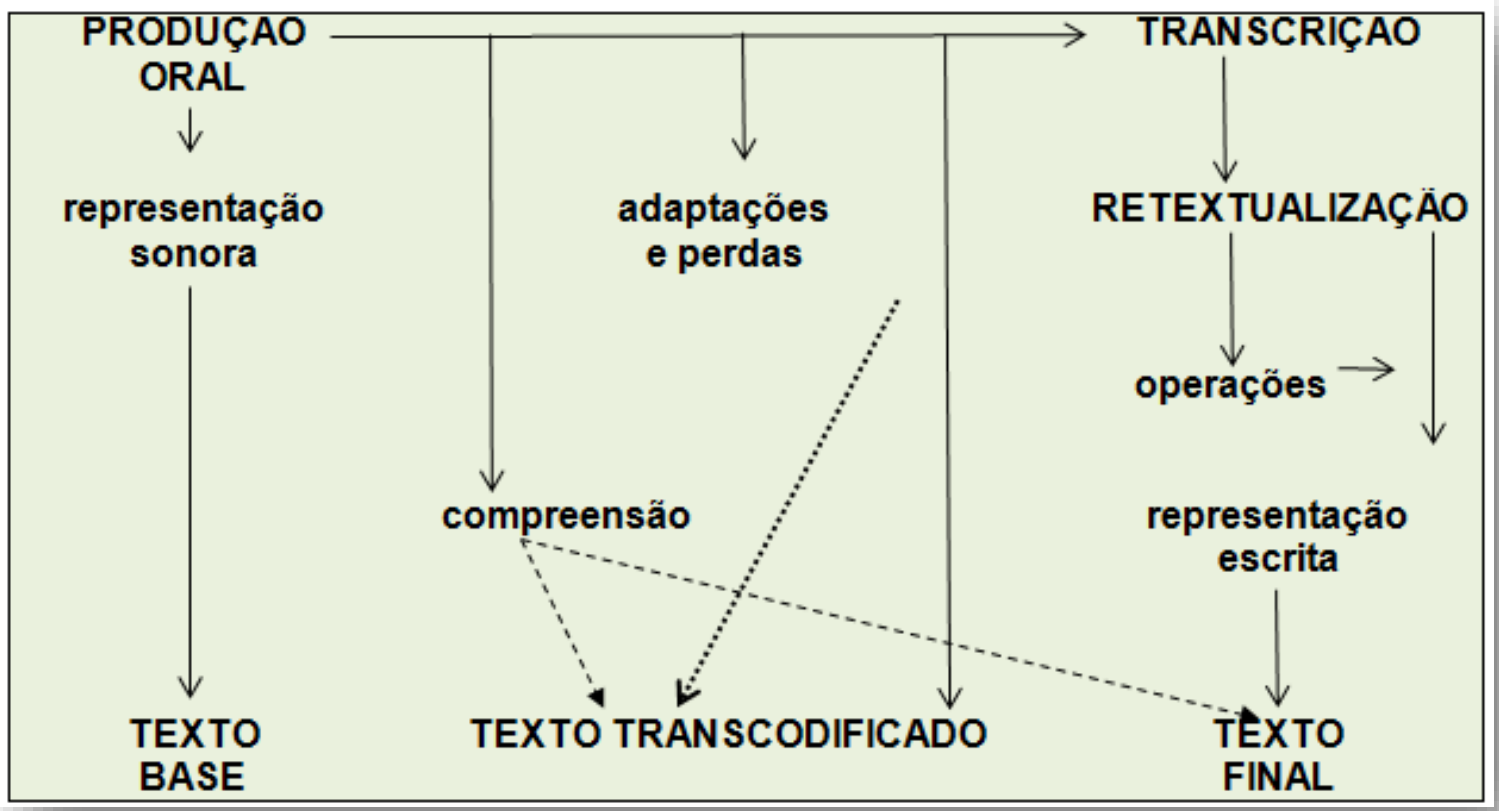

Fonte: Marcuschi (2010, p. 72).

Com efeito, a se considerar o processo de compreensão, as adaptações e as perdas, bem como as múltiplas operações envolvidas na passagem do texto-base (oral) ao texto-final (escrito), há de se convir que a retextualização pode se tornar uma atividade até mesmo perigosa, conforme mostrou Nascimento (2007), ao tratar desse fenômeno como instrumento de manipulação no discurso jurídico penal.

\subsubsection{Modelo das operações de retextualização da fala para a escrita}

Mesmo ciente do risco a que está propenso quem constrói um padrão de operacionalização de determinado fenômeno, Marcuschi (2010) propõe um modelo das operações de retextualização, alertando para o fato de que não se trata de uma fórmula, além de esclarecer que o modelo merece vários reparos do ponto de vista de sua operacionalidade. O modelo agrupa nove operações que contemplam apenas os aspectos textual-discursivos envolvidos nas atividades de idealização (eliminação, completude e regularização) e reformulação (acréscimo, substituição e reordenação) do texto escrito a partir do texto oral, conforme se pode verificar no quadro a seguir. 
Fig. 4 - Modelo das operações textual-discursivas na passagem do texto oral para o texto escrito

\begin{tabular}{|c|c|}
\hline $1^{a}$ operação & $\begin{array}{l}\text { Eliminação de marcas estritamente interacionais, } \\
\text { hesitações e partes de palavras (estratégia de eliminação } \\
\text { baseada na idealização linguística). }\end{array}$ \\
\hline $2^{\text {a }}$ operação: & $\begin{array}{l}\text { Introdução da pontuação com base na intuição fornecida } \\
\text { pela entoação das falas (estratégia de inserção em que a } \\
\text { primeira tentativa segue a sugestão da prosódia). }\end{array}$ \\
\hline $3^{a}$ operação: & $\begin{array}{l}\text { Retirada de repetições, reduplicações, redundâncias, } \\
\text { paráfrases e pronomes egóticos (estratégia de eliminação } \\
\text { para uma condensação linguística). }\end{array}$ \\
\hline $4^{\mathrm{a}}$ operação: & $\begin{array}{l}\text { Introdução de paragrafação e pontuação detalhada sem } \\
\text { modificação da ordenação dos tópicos discursivos } \\
\text { (estratégia de inserção). }\end{array}$ \\
\hline $5^{9}$ operação: & $\begin{array}{l}\text { Introdução de marcas metalinguísticas para referenciação } \\
\text { de ações e verbalização de contextos expressos por dêitico } \\
\text { (estratégia de reformulação objetivando explicitude) }\end{array}$ \\
\hline $6^{\mathrm{a}}$ operação: & $\begin{array}{l}\text { Reconstrução de estruturas truncadas, concordâncias, } \\
\text { reordenação sintática, encadeamentos (estratégia de } \\
\text { reconstrução em função da norma escrita). }\end{array}$ \\
\hline $7^{8}$ operação: & $\begin{array}{l}\text { Tratamento estilístico com seleção de novas estruturas } \\
\text { sintáticas e novas opções lexicais (estratégia de } \\
\text { substituição visando a uma maior formalidade). }\end{array}$ \\
\hline $8^{\mathrm{a}}$ operação: & $\begin{array}{l}\text { Reordenação tópica do texto e reorganização da sequência } \\
\text { argumentativa (estratégia de estruturação argumentativa). }\end{array}$ \\
\hline $9^{a}$ operação: & $\begin{array}{l}\text { Agrupamento de argumentos condensando as ideias } \\
\text { (estratégia de condensação). }\end{array}$ \\
\hline
\end{tabular}

Fonte: Marcuschi, 2010, p. 75 (com adaptações).

Marcuschi (2010) chama atenção para o fato de as operações de 1 a 4 ainda não se configuram como operações de transformação propriamente ditas. Por outro lado, as operações de 5 a 9 - que figuram no modelo - dizem respeito a um tratamento da fala (de natureza sintática, semântica, pragmática e cognitiva).

\subsection{Relação entre retextualização e fenômenos assemelhados}

A bem da verdade, a ideia de retextualização reveste-se de certa complexidade. Como se não bastasse, a situação torna-se ainda mais complexa quando a relacionamos às noções de reescrita, refacção e revisão, haja vista as fronteiras tênues entre elas. No senso comum, esses quatro fenômenos muitas vezes são tomados como sinônimos ou parassinônimos; no entanto, do ponto de vista teórico-metodológico, essas atividades nem sempre se equivalem.

A respeito da retextualização, há registro de que a expressão foi empregada por Neusa Travaglia, em 1993, na sua tese de doutorado sobre a tradução de uma língua para outra. Marcuschi (2010), em uma nota de rodapé de seu livro, explica que o foco do seu estudo naquela ocasião retoma a expressão cunhada pela referida autora, porém tratando a retextualização como uma

https://periodicos.unifap.br/index.php/letras

Macapá, v. 9, n. 4, $2^{0}$ sem., 2019 
espécie de tradução endolíngue. Na mesma nota de pé de página, Marcuschi (2010, p. 46) sinaliza a questão da refaç̧ão e da reescrita, ao dizer que ambas "observam aspectos relativos às mudanças de um texto no seu interior (uma escrita para outra, reescrevendo o mesmo texto) sem envolver as variáveis que incidem no caso da retextualização (...)".

Posteriormente, Matencio (2002, p. 113) retoma e discute essa questão, afirmando

que a reescrita "é atividade na qual, através do refinamento dos parâmetros discursivos, textuais e linguísticos que norteiam a produção original, materializa-se uma nova versão do texto". Desta feita, a reescrita não implica a produção de um novo texto, mas de uma nova versão de um texto já produzido, ou seja, trata-se de operar sobre o mesmo construto textual, para transformálo, sem haver mudança de propósito comunicativo. D’Andrea e Ribeiro (2010, p. 66) sustentam que "a reescrita, diferentemente [da retextualização], só poderia ocorrer do escrito para o escrito. Dessa distinção, pode-se propor que toda retextualização é reescrita, mas nem toda reescrita gera uma retextualização".

Quanto à refacção, o que encontramos sobre este fenômeno é uma perspectiva que o aproxima da reescrita. Marcuschi (2010) afirma que refacção e reescrita estão circunscritas a mudanças realizadas no interior do texto. Para D'Andrea e Ribeiro (2010, p. 67), “certamente, o propósito da refacção (de refazer, um verbo também abrangente, bem mais do que reescrever) orienta as operações empreendidas no texto assim como as relações tipológicas no gênero (...)". Em Matencio (2002), também numa nota de rodapé, encontramos uma referência à refacção como um processo que envolve a reescrita/revisão de textos produzidos por alunos em situações de ensino/aprendizagem. Assemelhando-se à visão de Marcuschi (2010), Silveira (2008, p. 173) assevera que "a refacção ou reescrita assemelha-se mais a uma higienização do texto, incluindo reestruturação e revisão estilística e gramatical". De qualquer maneira, não se pode negar que o processo de refacção abarca o de reescrita, porém é provável que este não recubra aquele, que se configura como um fenômeno mais amplo.

No que concerne à revisão, Matencio (2002) alerta-nos para o fato de que é desejável que esta deva ser tratada como uma atividade distinta da reescrita, muito embora a autora reconheça que, no âmbito do ensino/aprendizagem, não exista uma distinção entre essas duas atividades, entendidas como etapas sucessivas do processo de refacção textual. D'Andrea e Ribeiro (2010), tratando da revisão no campo editorial, mostram a complexidade da questão, discorrendo sobre as múltiplas vertentes que o processo de revisão pode desencadear. Nesse prisma, entendemos que, a depender do ponto de vista adotado, a revisão pode ir de uma atividade de correção formal da linguagem a um patamar mais amplo, se levarmos em consideração outros fatores de ordem pragmática ou até mesmo discursiva.

\section{CONSIDERAÇÕES FINAIS}

Tentamos esclarecer o conceito de retextualização de forma mais ou menos acessível ao público iniciante, mostrando as várias possibilidades de retextualização e a sua recorrência nos múltiplos domínios discursivos. Uma preocupação nossa com este trabalho foi mostrar que a Marcuschi - com sua publicação seminal nos anos dois mil - deve-se o pioneirismo dos estudos sobre retextualização no Brasil. Entretanto, de lá para cá, muito já se avançou na pesquisa sobre o tema, tal como referenciamos produções relativamente recentes que trazem esse fenômeno como objeto de estudo. Em suma, os caminhos por aqui percorridos ratificam que o tema é complexo e profícuo; por conseguinte, cabe aos profissionais que trabalham com ensino de línguas estudar essa questão, pois ela certamente renderá bons frutos ao fazer pedagógico nas aulas de linguagem.

\section{REFERÊNCIAS}

ABASSE, M. C. J. P. A produção do resumo-escolar como resultado da atividade de retextualizaçãa. 2008. 136

https://periodicos.unifap.br/index.php/letras

Macapá, v. 9, n. 4, $2^{\circ}$ sem., 2019 
f. Dissertação (Mestrado em Linguística) - Universidade Federal de Minas Gerais, Belo Horizonte, 2008.

ALVES, F. O. Retextualização: da escrita para a fala e da fala para a escrita - o caso das atas. 2015. 218 f. Dissertação (Mestrado em Filologia e Língua Portuguesa) - Universidade de São Paulo, São Paulo, 2015.

BEAUGRANDE, R. New foundations for a Science of text and discourse: cognition, communication and freedom of access to knowledge and society. Norwood, New Jersey: Ablex Publishing Corporation, 1997.

BEAUGRANDE, R.; DRESSLER, W. Introduction to text linguistics. London: Longman, 1981.

BENFICA, M. F. M. B. A noção de gênero e a retextualização: implicações pedagógicas. In: DELL'ISOLA, R. L. P (Org.). Gêneros textuais: o que há por trás do espelho? FALE/UFMG: Belo Horizonte, 2012. p. 29-37.

CAVALCANTI, R. J. S. Análise textual-argumentativa de processos de retextualização: um cotejo entre a produção oral e escrita de alunos do curso médio integrado e alunos do PROEJA ensino médio. 2016. 320 f. Tese (Doutorado em Linguística) - Universidade Federal de Alagoas, Maceió, 2016.

D'ANDREA, C. F. B.; RIBEIRO, A. E. Retextualizar e reescrever, editar e revisar: reflexões sobre a produção de textos e as redes de produção editorial. Veredas, Juiz de Fora, v. 14, n. 1, p. 64-74, 2010.

DEMÉTRIO, A. P. C. A tradução como retextualização: uma proposta para o desenvolvimento da produção textual e para a ressignificação da tradução dentro do ensino de LE. 2014. 198 f. Dissertação (Mestrado em Estudos da Tradução) - Universidade Federal de Santa Catarina, Florianópolis, 2014.

DIKSON, D. Da escrita para a escrita: aspectos e processos em retextualização. Recife: EDUFRPE, 2019.

KOCH, I. G. V. Introdução à linguística textual: trajetória e grandes temas. 2. ed. São Paulo: W M F Martins Fontes, 2009.

MARCUSCHI, L. A. Da fala para a escrita: atividades de retextualização. 10. ed. São Paulo: Cortez, 2010.

MATENCIO, M. L. M. Referenciação e retextualização de textos acadêmicos: um estudo do resumo e da resenha. Anais do III Congresso Internacional da ABRALIN, março de 2003.

MATENCIO, M. L. M. Atividades de retextualização em práticas acadêmicas: um estudo do gênero resumo. Scripta, Belo Horizonte, v. 6, n. 11, p. 25-32, 2002.

MOURA, G. R. P. A retextualização de material didático para o ensino fundamental de nivel técnico como uma modalidade de tradução intralingual numa perspectiva semiolinguística. 2011. 234 f. Dissertação (Mestrado em Linguística) - Universidade Federal de Minas Gerais, Belo Horizonte, 2011.

NASCIMENTO, A. B. A retextualização como instrumento de manipulação no discurso jurídico penal. 2007. 182 f. Dissertação (Mestrado em Linguística) - Universidade Federal de Minas Gerais, Belo Horizonte, 2007.

NUNES, V. S. Gênero textual na esfera jornalística. São Paulo: Pá de Palavra, 2020.

NUNES, V. S. Da imagem à palavra: processo de retextualização em aula de língua portuguesa na educação básica. Desafios, Palmas, n. 4, v. 4, p. 93-101, 2017.

NUNES, V. S.; SILVEIRA, M. I. M. Da escrita para a escrita: processos de retextualização na carta do leitor. Letras Raras, Campina Grande, v. 6, n. 2, p. 115-131, 2017.

OLIVEIRA, M. C. A retextualização de texto do gênero infográfico: uma análise da estrutura retórica. 2010. 104 f. Dissertação (Mestrado em Linguística) - Universidade Federal de Minas Gerais, Belo Horizonte, 2010.

OLIVEIRA, M. R. Discurso parlamentar: estratégias de retextualização. 2009. 122 f. Dissertação (Mestrado em Língua Portuguesa) - Pontifícia Universidade Católica de São Paulo, São Paulo, 2009.

SANTOS, A. M. T. A retextualização na construção do discurso jurídico acadêmico. 2006. 116 f. Dissertação (Mestrado em Ciências da Linguagem) - Universidade Católica de Pernambuco, Recife, 2006.

https://periodicos.unifap.br/index.php/letras

Macapá, v. 9, n. 4, $2^{\circ}$ sem., 2019 
SILVA, A. V. L. Com a palavra, o aluno: processos de retextualização na exposição oral acadêmica. 2013. 230 f. Tese (Doutorado em Estudos Linguísticos) - Universidade Federal de Minas Gerais, Belo Horizonte, 2013.

SILVEIRA, M. I. M. Retextualização: aspectos teóricos e práticos. In: CAVALCANTE, M. A.; FREITAS, M. L. Q. (Org.). O ensino da lingua portuguesa nos anos iniciais: eventos e práticas de letramento. Maceió: EDUFAL, 2008. p. 169-178.

Recebido em: 24/08/2017

Aprovado em: 09/12/2017 